\title{
Vasonatrin Peptide: A Unique Synthetic Natriuretic and Vasorelaxing Peptide
}

Chi-Ming Wei, Cheol H. Kim, Virginia M. Miller, and John C. Burnett, Jr. Cardiorenal Research Laboratory, Divisions of Cardiovascular Diseases and Cardiovascular Surgery, and Department of Physiology and Biophysics, Mayo Clinic and Foundation, Rochester, Minnesota 55905

\begin{abstract}
This study reports the cardiovascular and renal actions of a novel and newly synthesized 27 -amino acid peptide termed vasonatrin peptide (VNP). VNP is a chimera of atrial natriuretic peptide (ANP) and C-type natriuretic peptide (CNP). This synthetic peptide possesses the 22-amino acid structure of CNP, which is a cardiovascular selective peptide of endothelial origin and is structurally related to ANP. VNP also possesses the five-amino acid $\mathrm{COOH}$ terminus of ANP. The current study demonstrates both in vitro and in vivo that VNP possesses the venodilating actions of $\mathrm{CNP}$, the natriuretic actions of ANP, and unique arterial vasodilating actions not associated with either ANP or CNP. (J. Clin. Invest. 1993. 92:20482052.) Key words: Natriuretic peptide • vasorelaxation • endothelium • cardiorenal function • cGMP
\end{abstract}

\section{Introduction}

Atrial natriuretic peptide (ANP) ${ }^{1}$ is a 28 -amino acid peptide that contains a 17-amino acid ring structure and is secreted from atrial myocytes (Fig. 1). ANP possesses natriuretic and vasoactive actions and is important in the control of cardiorenal homeostasis (1-3). ANP mediates its biological actions via a specific ANP receptor (ANPR-A) (4) that is expressed in endothelial cells and in renal epithelial cells (5). Currie et al. (6) have previously demonstrated that the vasoactive and natriuretic actions of ANP require its $\mathrm{COOH}$ terminus.

C-type natriuretic peptide (CNP) is a newly identified 22amino acid peptide (Fig. 1) that like ANP has a 17-amino acid ring formed by a disulfide bond but is genetically distinct (7). Unlike ANP, CNP lacks the COOH-terminal amino acid extension from the ring structure. CNP functions biologically via a separate receptor (ANPR-B) (4) that is expressed in vascular smooth muscle cells and in the kidney (8). While ANP and CNP both decrease cardiac preload and arterial pressure, they may involve different mechanisms $(9,10)$. Specifically, ANPmediated decreases in arterial pressure are in part secondary to increases in sodium excretion, which is minimal with CNP. In

\footnotetext{
Address correspondence to Dr. Chi-Ming Wei, G-915, Mayo Clinic and Foundation, 200 First Street SW, Rochester, MN 55905. 1993.

Received for publication 2 Anril 1993 and in revised form 3 June
}

1. Abbreviations used in this paper: ANP, atrial natriuretic peptide;

CNP, c-type natriuretic peptide; VNP, vasonatrin peptide.

The Journal of Clinical Investigation, Inc.

Volume 92, October 1993, 2048-2052 contrast, CNP is a potent venodilator and ANP is not (11). Further, ANP is of cardiac origin and functions as a circulating hormone. In contrast, CNP is synthesized and released from endothelial cells (12-14), consistent with a paracrine role in the control of vascular tone (11).

The differences in biological activity and receptor binding for ANP and CNP may be in part due to the presence or absence of a $\mathrm{COOH}$ terminus. We hypothesized that addition of the $\mathrm{COOH}$ terminus from ANP to CNP would result in a unique peptide with biological actions of both ANP and CNP. Specifically, we hypothesized that such a synthetic peptide would have combined actions of venodilation and natriuresis. Therefore, the present studies were designed to synthesize this peptide, termed vasonatrin peptide (VNP), and determine its vascular and renal actions in vivo and in vitro, thus creating a chimera of ANP and CNP, which are each homologous polypeptide hormones.

\section{Methods}

Peptide synthesis. Fig. 1. illustrates the structures of ANP, CNP, and the new peptide, VNP. As shown in Fig. 1, VNP is 27-amino acid that consists of the 22-amino acid ringed structure of CNP with the ANP $\mathrm{COOH}$-terminal 5-amino acid extension. The molecular weight of VNP is 2,837 . VNP was synthesized in the Mayo Protein Core Facility using fluorenylmethoxy-carbonyl (FMOC) chemistry on a peptide synthesizer (model ABI 431 A; Applied Biosystems, Inc., Foster City, CA) with the protocols and reagents supplied by the manufacturer. The peptide was purified by reverse phase HPLC using a Vydac $C 8$ column (The Separations Group, Hesperia, CA). Synthesis was confirmed by amino acid analysis and plasma absorption mass spectrometry.

Reverse Phase HPLC. The samples from the plasma were analyzed using reverse phase HPLC with a Vydac $C 18$ column $(4.6 \times 250 \mathrm{~mm}$; The Separations Group). The components of the HPLC system were two pumps (model 114; Beckman Instruments, Inc., San Ramon, CA), an absorbance detector (model ABI 759A; Applied Biosystems, Inc.), and an IBM PS2 $50 Z$ computer with Beckman System Gold Chromatography software. The A buffer was $0.1 \%$ trifluoroacetic acid and the B buffer was $80 \%$ acetonitrile, $20 \%$ water, $0.1 \%$ trifluoroacetic acid. The separation was performed with a gradient of 5-70\% B buffer in $60 \mathrm{~min}$.

In vitro studies. Rings cut from femoral, saphenous, and renal arteries, and veins obtained from random source mongrel dogs (anesthetized with $30 \mathrm{mg} / \mathrm{kg}$ pentobarbital sodium intravenously) were suspended for the measurement of isometric force in organ chambers filled with aerated $\left(95 \% \mathrm{O}_{2}\right.$ and $\left.5 \% \mathrm{CO}_{2}\right)$ modified Krebs-Ringer bicarbonate solution (composition in $\mathrm{mM}: 118.3 \mathrm{NaCl}, 4.7 \mathrm{KCl}, 2.5 \mathrm{CaCl}_{2}$, $1.2 \mathrm{MgSO}_{4}, 1.2 \mathrm{KH}_{2} \mathrm{PO}_{4}, 25.0 \mathrm{NaHCO}_{3}, 0.026$ calcium sodium EDTA, and 11.1 dextrose; control solution ) at $37^{\circ} \mathrm{C}$. In one-half of the rings, the endothelium was removed by gently rubbing the intimal surface with a cotton swab wet with control solution. Each ring was stretched to the optimal point on its length-tension curve as determined by the tension developed to norepinephrine $\left(3 \times 10^{-7} \mathrm{M}\right)$ at 
each level of stretch. The presence of endothelium was determined at the beginning of the experiment by relaxation to acetylcholine $\left(10^{-6}\right.$ M) during a contraction to norepinephrine at optimal length. The maximal tension of each ring was determined by norepinephrine $\left(10^{-4}\right.$ $M)$. To study responses to the ANP, CNP, and VNP, the rings were contracted with phenylephrine $\left(10^{-6} \mathrm{M}\right)$. These contractions averaged $30-40 \%$ of the maximal contraction to norepinephrine. The peptides were added cumulatively once the contraction had stabilized.

The following drugs were used: acetylcholine chloride (Sigma Chemical Co., St. Louis, MO), human ANP and human CNP (Peninsula Laboratories, Belmont, CA), VNP (Mayo Clinic, Rochester, MN), L-norepinephrine bitartrate (Sigma Chemical Co.), and phenylephrine bitartrate (Sigma Chemical Co.). All drugs were dissolved in distilled water immediately before study, and the concentrations are reported as the final molar concentration in the organ chamber.

In vivo studies. Experiments were conducted in accordance with the Animal Welfare Act. Wistar rats ( $400 \mathrm{~g}$; Harlan Sprague-Dawley, Indianapolis, IN ) were anesthetized with inactin ( $100 \mathrm{mg} / \mathrm{kg}$ i.p.; BYK Gulden, Konstanz, Germany). The body temperature was maintained between 36 and $38^{\circ} \mathrm{C}$ by a heating pad. Tracheostomy was performed; however, the animals were not artificially ventilated. Polyethylene catheters (PE-50; Becton Dickinson \& Co., Parsippany, NJ) were placed in the left jugular vein for infusions of saline and drugs, in the right jugular vein to right atrium to monitor right atrial pressure, and in the carotid artery for the collection of blood samples and to monitor mean arterial pressure. A PE-90 catheter (Becton Dickinson \& Co.) was placed in the bladder for urine collection.

Experiments were conducted in three groups: ANP $(n=4)$, CNP $(n=4)$, and VNP $(n=4)$. Intravenous infusions of saline solution $(0.9 \% \mathrm{NaCl})$ were performed $(1 \mathrm{ml} / 100 \mathrm{gm}$ body weight per $\mathrm{h})$ through the left jugular vein catheter. After completion of surgery, rats were allowed to stabilize for $30 \mathrm{~min}$. In each group a 15 -min baseline period followed. After the baseline period, saline solution $(0.9 \% \mathrm{NaCl})$ was administered in a bolus fashion $(0.1 \mathrm{ml})$ and was followed by a 15-min period. After the saline period, the peptide (ANP, CNP, or VNP) was administered in a bolus fashion $(0.1 \mathrm{ml})$ at $5 \mu \mathrm{g} / \mathrm{kg}$, which was followed by a 15 -min period. This was followed by a second bolus $(0.1 \mathrm{ml})$ at $50 \mu \mathrm{g} / \mathrm{kg}$ and a $15-\mathrm{min}$ period. After a 30-min washout, a 15-min recovery period followed. During each experimental period, mean arterial pressure (MAP), heart rate (HR), and right atrial pressure (RAP) were measured. At the midpoint of baseline, second bolus $(50 \mu \mathrm{g} / \mathrm{kg}$ ), and recovery periods, blood was sampled for plasma guanosine 3',3'-cyclic monophosphate (cGMP). At the end of each period, urine was measured for volume (UV), and samples were stored for electrolytes and CGMP analysis.

Blood for plasma cGMP analysis was collected into EDTA tubes, immediately placed on ice, and centrifuged at $2,500 \mathrm{rpm}$ at $4^{\circ} \mathrm{C}$. Plasma was separated and stored at $-20^{\circ} \mathrm{C}$ until assay. Urine for cGMP determination was heated to $>90^{\circ} \mathrm{C}$ before storage. Plasma and urine cGMP were determined by a specific RIA as previously described (15).

Statistical analysis. The results are expressed as the means \pm SEM. In organ chamber studies, $n$ equals the number of dogs from which rings were taken. Rings with and without endothelium were studied in parallel, and Student's $t$ test for unpaired observations was used to determine statistical significance among the responses of rings with and without endothelium and between responses of arteries and veins. In rat studies, the data were analyzed using analysis of variance (ANOVA) for repeated measures followed by Fisher's least significant difference test when appropriate within the group. Data between groups were analyzed by Student's unpaired $t$ test. Statistical significance was determined at $P<0.05$.

\section{Results}

Representative concentration-response curves in isolated canine femoral arteries and veins to ANP, CNP, and VNP are illustrated in Fig. 2. At maximal dose $\left(3 \times 10^{-6} \log \mathrm{M}\right)$, ANP and CNP resulted in no relaxation in femoral arteries contracted with phenylephrine. VNP, however, caused in potent relaxation (90-100\%) in femoral arteries. In femoral veins, ANP had no effect. CNP and VNP mediated $90 \%$ relaxations in femoral veins.

Table I summarizes the maximal relaxations $\left(3 \times 10^{-6} \mathrm{M}\right)$ of ANP, CNP, and VNP in isolated canine blood vessels. In systemic arteries (femoral, saphenous, and renal), ANP and CNP produced modest relaxations with the maximum $<30 \%$ of the contraction to phenylephrine. VNP, in contrast, produced relaxations that ranged between 50 and $90 \%$ of the contraction; these relaxations were not modified by the endothelium. In the comparable systemic veins, relaxations to CNP were greater than relaxations evoked by ANP. Relaxations to CNP were increased by removal of the endothelium. Relaxations to VNP were greater than those to CNP in all systemic veins tested; in the renal veins, the relaxations were enhanced by removal of the endothelium. The potency for relaxation in the systemic blood vessels for the peptides can be summarized as: VNP $>$ ANP $\geq$ CNP in arteries; VNP $>$ CNP $>$ ANP in veins.

Table II summarizes the cardiovascular and renal actions of ANP, CNP, and VNP in Wistar rats. Bolus administration (0.1 $\mathrm{ml}$ ) of saline vehicle had no cardiovascular or renal actions. Bolus administration $(0.1 \mathrm{ml})$ of high-dose $(50 \mu \mathrm{g} / \mathrm{kg})$ ANP, CNP, and VNP resulted in decrease in mean arterial pressure and right arterial pressure, and increase in urine flow, sodium excretion, plasma cGMP, and urinary cGMP excretion. The increase in urine flow, sodium excretion, and urinary cGMP were higher with VNP than those of CNP, but were less than those of ANP.

To determine whether the pharmacological effects of VNP are mediated by the intact peptide or by degradative products, HPLC was used to define the molecular form of the peptide in plasma and in the injected solution (Fig. 3). Fig. $3 A$ illustrates the peak of VNP in normal saline before injection. Fig. $3 B$ illustrates no presence of VNP peak in rat plasma before VNP injection. Fig. $3 C$ illustrates the appearance of VNP peak in

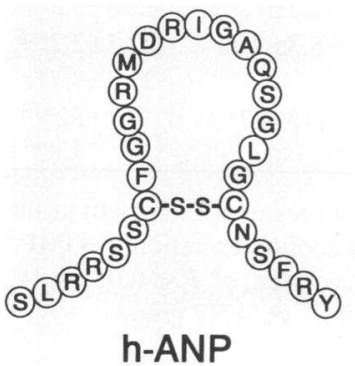

h-ANP

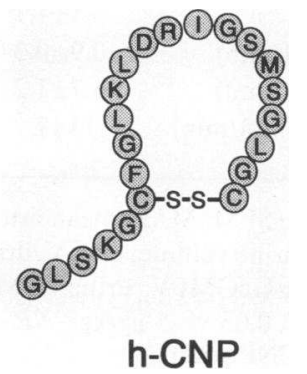

h-CNP

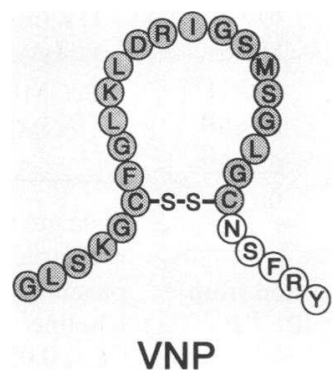

Figure 1. The structures of human atrial natriuretic peptide ( $h-A N P$ ), human C-type natriuretic peptide $(h-C N P)$, and vasonatrin peptide $(V N P)$. 


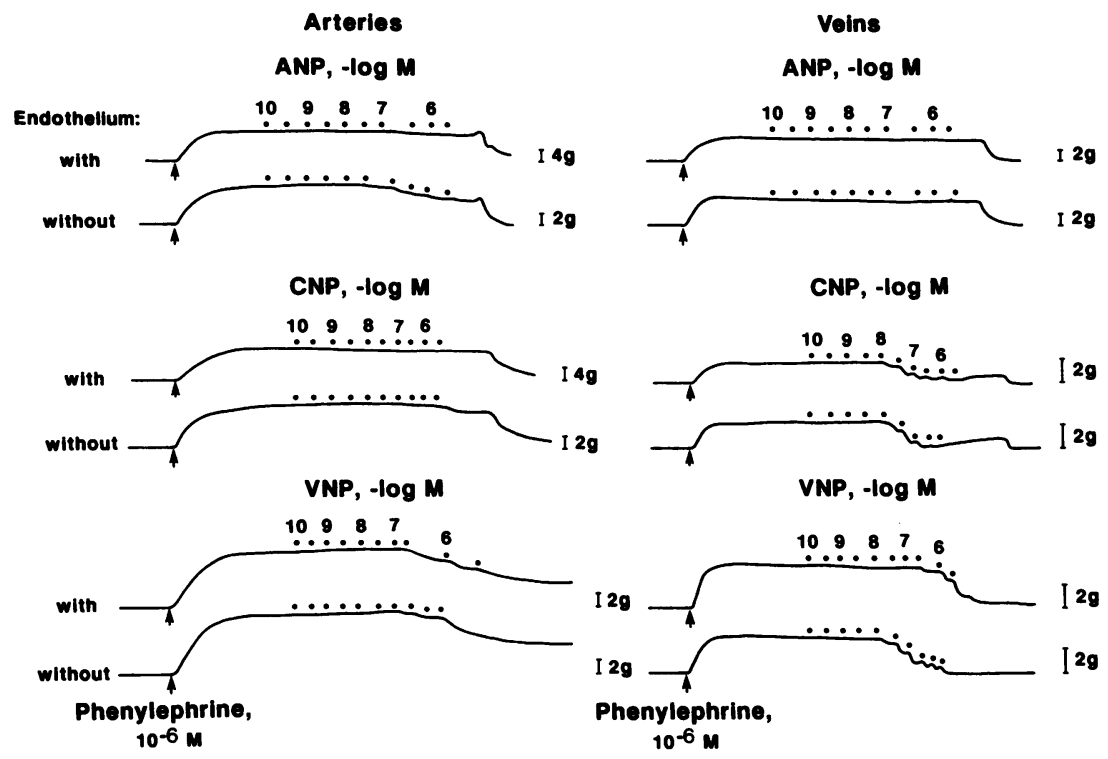

Figure 2. Concentration-dependent responses of femoral arteries and veins with and without endothelium to ANP, CNP, and VNP. the rat plasma $5 \mathrm{~min}$ after the high-dose bolus injection of VNP $(50 \mu \mathrm{g} / \mathrm{kg})$. At this time the VNP peak is shifted to the right. However, analysis of the amino acid sequence of the peak was identical to mature VNP. No peak corresponding to VNP was observed in the plasma during the recovery period (Fig. $3 \mathrm{D}$ ), which was 30 min after the VNP bolus.

\section{Discussion}

This study reports for the first time the vascular and natriuretic actions of a new synthetic vasoactive and natriuretic peptide, termed VNP, that represents the 22-amino acid ringed structure of CNP and the COOH terminus of ANP. Moreover, this new peptide is a more potent, endothelium-independent vaso-

Table I. The Maximal Responses

of $A N P, C N P$, and VNP $\left(3 \times 10^{-6} \mathrm{M}\right)$

in Isolated Normal Canine Blood Vessels

\begin{tabular}{|c|c|c|c|c|}
\hline Arteries & Endothelium & $\begin{array}{c}\text { ANP } \\
(n=6-9)\end{array}$ & $\begin{array}{c}\text { CNP } \\
(n=6-9)\end{array}$ & $\begin{array}{c}\text { VNP } \\
(n=4-6)\end{array}$ \\
\hline \multicolumn{5}{|l|}{ Arteries } \\
\hline \multirow[t]{2}{*}{ Femoral } & With & $10 \pm 5^{*}$ & $4 \pm 3$ & $91 \pm 4^{ \pm 8}$ \\
\hline & Without & $19 \pm 12$ & $10 \pm 6$ & $89 \pm 5^{55}$ \\
\hline \multirow[t]{2}{*}{ Saphenous } & With & $0 \pm 0$ & $11 \pm 7$ & $73 \pm 3^{\ddagger 5}$ \\
\hline & Without & $3 \pm 3$ & $14 \pm 8$ & $81 \pm 5^{58}$ \\
\hline \multirow[t]{2}{*}{ Renal } & With & $27 \pm 6^{8}$ & $8 \pm 2$ & $52 \pm 4^{\ddagger 8}$ \\
\hline & Without & $30 \pm 6^{8}$ & $8 \pm 2$ & $62 \pm 12^{ \pm 5}$ \\
\hline \multicolumn{5}{|l|}{ Veins } \\
\hline \multirow[t]{2}{*}{ Femoral } & With & $6 \pm 3$ & $37 \pm 8^{\ddagger}$ & $81 \pm 6^{\text {t8 }}$ \\
\hline & Without & $4 \pm 4$ & $73 \pm 8^{ \pm 11}$ & $86 \pm 6^{\ddagger}$ \\
\hline \multirow[t]{2}{*}{ Saphenous } & With & $0 \pm 0$ & $16 \pm 1^{\ddagger}$ & $60 \pm 11^{\text {เ8 }}$ \\
\hline & Without & $0 \pm 0$ & $43 \pm 10^{\ddagger}$ & $89 \pm 6^{ \pm 3}$ \\
\hline \multirow[t]{2}{*}{ Renal } & With & $12 \pm 3$ & $43 \pm 4^{\ddagger}$ & $65 \pm 6^{\ddagger \S}$ \\
\hline & Without & $11 \pm 4$ & $71 \pm 5^{ \pm \| 1}$ & $90 \pm 4^{ \pm \$|1|}$ \\
\hline
\end{tabular}

* Data are shown as mean \pm SEM of a percent change in tension from a contraction to phenylephrine $\left(10^{-6} \mathrm{M}\right)$. ${ }^{\ddagger} P<0.05$ vs. ANP. ${ }^{8} P$ $<0.05$ vs. CNP. " $P<0.05$ vs. with endothelium. relaxing peptide in both arteries and veins as compared with ANP and CNP.

Previous studies demonstrated that ANP is a potent natriuretic and vasoactive peptide that functions via activation of cGMP $(2,10,11)$ by stimulating of ANPR-A (4). ANP has vasorelaxing actions in renal and pulmonary arteries $(13,16)$. This investigation confirms these renal and vascular actions of

Table II. The Cardiorenal Actions of ANP, CNP, and VNP in Normal Rats

\begin{tabular}{|c|c|c|c|}
\hline Group & Baseline & $5 \mu \mathrm{g} / \mathrm{kg}$ & $50 \mu \mathrm{g} / \mathrm{kg}$ \\
\hline \multicolumn{4}{|l|}{$\operatorname{ANP}(n=4)$} \\
\hline MAP (mmHg) & $119 \pm 14$ & $97 \pm 12^{*}$ & $69 \pm 7^{* \pm}$ \\
\hline $\mathrm{RAP}(\mathrm{mmHg})$ & $0.8 \pm 1.6$ & $-2.3 \pm 0.8^{*}$ & $-3.8 \pm 0.8^{* \pm}$ \\
\hline $\mathrm{UV}(\mu \mathrm{l} / \mathrm{min})$ & $6.7 \pm 1.2$ & $79 \pm 10^{*}$ & $341 \pm 41^{* \neq}$ \\
\hline $\mathrm{UNaV}(\mu \mathrm{mol} / \mathrm{min})$ & $0.4 \pm 0.1$ & $13.2 \pm 3.5^{*}$ & $68.2 \pm 15.7^{\text {*\# }}$ \\
\hline PcGMP (pmol/ml) & $4.1 \pm 0.7$ & - & $25.7 \pm 7.1^{*}$ \\
\hline UcGMPV (pmol/min) & $11 \pm 2$ & $605 \pm 151^{*}$ & $2,580 \pm 505^{* \neq}$ \\
\hline \multicolumn{4}{|l|}{$\mathrm{CNP}(n=4)$} \\
\hline MAP (mmHg) & $116 \pm 11$ & $100 \pm 12^{*}$ & $87 \pm 9 * \neq$ \\
\hline RAP (mmHg) & $1.2 \pm 0.9$ & $0 \pm 1.5$ & $-2.3 \pm 0.6^{*}$ \\
\hline $\mathrm{UV}(\mu \mathrm{l} / \mathrm{min})$ & $5.7 \pm 0.5$ & $27.6 \pm 2.0^{* \delta}$ & $66.4 \pm 7.4^{* \neq 8}$ \\
\hline $\mathrm{UNaV}(\mu \mathrm{mol} / \mathrm{min})$ & $0.6 \pm 0.2$ & $4.1 \pm 1.4^{8}$ & $12.1 \pm 3.2^{* \pm 8}$ \\
\hline PcGMP (pmol/ml) & $2.2 \pm 0.1$ & - & $19.4 \pm 2.7^{*}$ \\
\hline UcGMPV (pmol/min) & $23 \pm 7$ & $97 \pm 32^{\S}$ & $323 \pm 81^{* \S}$ \\
\hline \multicolumn{4}{|l|}{$\operatorname{VNP}(n=4)$} \\
\hline MAP (mmHg) & $112 \pm 14$ & $93 \pm 15^{*}$ & $79 \pm 15^{* \pm}$ \\
\hline RAP (mmHg) & $-2.5 \pm 0.6$ & $-3.5 \pm 0.9$ & $-4.3 \pm 0.8^{*}$ \\
\hline $\mathrm{UV}(\mu \mathrm{l} / \mathrm{min})$ & $6.5 \pm 1.1$ & $32.2 \pm 7.5^{* 5}$ & $136 \pm 5.5^{*+5 ॥}$ \\
\hline $\mathrm{UNaV}(\mu \mathrm{mol} / \mathrm{min})$ & $0.9 \pm 0.3$ & $5.3 \pm 1.9$ & $22.5 \pm 2.2^{* \pm \$ ॥}$ \\
\hline PcGMP (pmol/ml) & $3.7 \pm 1.2$ & - & $33.3 \pm 8.7^{*}$ \\
\hline UcGMPV (pmol/min) & $13 \pm 7$ & $113 \pm 27^{* 5}$ & $961 \pm 82^{* \neq \xi 11}$ \\
\hline
\end{tabular}

Data are mean \pm SEM. MAP, mean arterial pressure; RAP, right atrial pressure; UV, urine volume; $\mathrm{UNaV}$, urine sodium excretion; PcGMP, plasma cGMP; UcGMPV, urine cGMP volume. ${ }^{*} P<0.05$ vs. baseline. ${ }^{\ddagger} P<0.05$ vs. $5 \mu \mathrm{g} / \mathrm{kg}$. ${ }^{\$} P<0.05$ vs. ANP group. " $P<0.05$ vs. CNP group. 

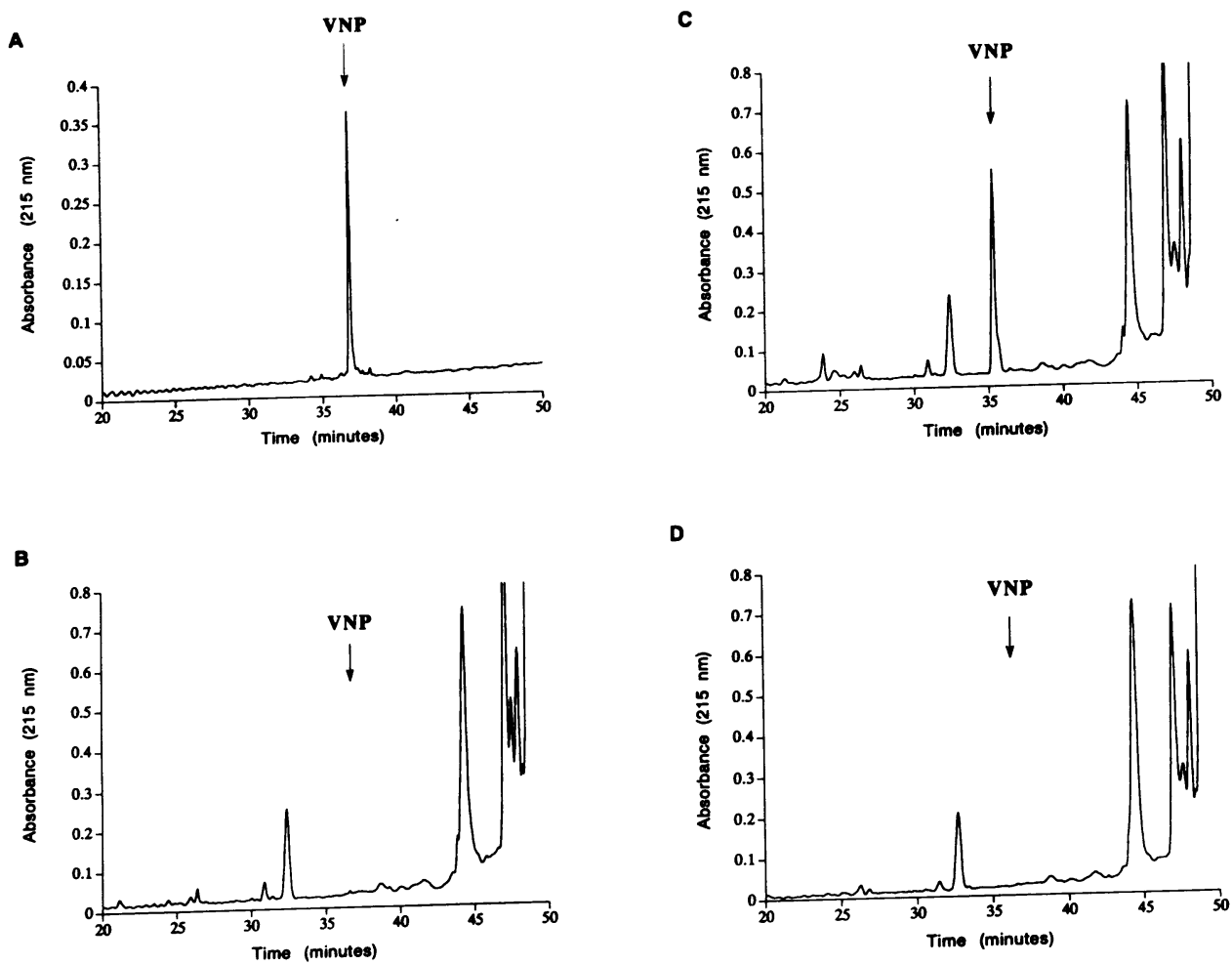

D

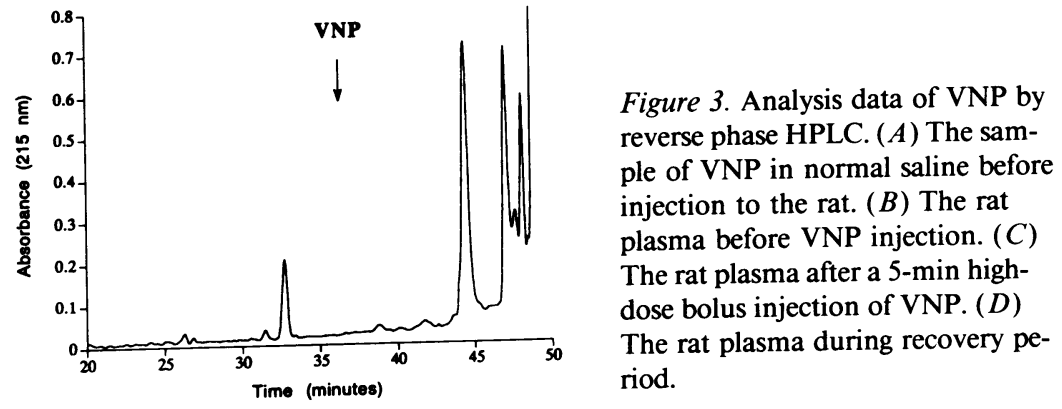

ANP in both organ chamber studies and rat studies. CNP has potent vasodilator actions in veins with less actions in arteries (11) and functions via activation of a guanylyl cyclase-linked receptor termed ANPR-B. Unlike ANP, CNP has minimal natriuretic actions $(9,10)$ that may in part be explained by the lack of CNP binding in the kidney (17), although studies have documented abundance of mRNA transcripts for ANPR-B in the rat kidney ( 8 ). In the present study, CNP has potent hemodynamic actions, as previously reported, and minimal natriuretic actions. This minimal natriuretic action may in part be explained by increases in ANP caused by CNP displacement of ANP from the clearance receptor (10).

The structural difference between ANP and CNP (Fig. 1) is a difference in amino acid sequences and an absence of a $\mathrm{COOH}$ terminus tail for CNP as noted for ANP. The new synthetic peptide, VNP, a chimera peptide of ANP and CNP, supports the conclusion that the $\mathrm{COOH}$ terminus may play a functionally important role for biological activity (6). Specifically, VNP demonstrated natriuretic actions like ANP and venodilating actions associated with CNP that in vitro were not observed with ANP. Moreover, VNP produced more potent arterial vasodilatation than either ANP or CNP. Further, in femoral veins CNP had more potent actions in vessels without endothelium, but VNP actions are similar with and without the endothelium. This may be due to endothelial mechanism(s) that inhibit the actions of CNP but not VNP. This may also be related to the presence of the $\mathrm{COOH}$ terminus.

VNP has potent venodilating and natriuretic actions. Thus, VNP mimics the pharmacological actions of both a diuretic and nitroglycerin, suggesting a unique therapeutic potential in cardiovascular diseases such as congestive heart failure and hypertension. It should also be underscored that VNP possesses unique arterial vasorelaxing actions not observed with either CNP or ANP, underscoring its therapeutic potential.
The mechanism of the paradoxical enhancement of vasorelaxation of arteries and veins when compared with ANP and CNP remains unclear. As VNP is a unique structure that is not found in nature, VNP may be more slowly degraded by neutral endopeptidase 24.11 and result in more prolonged interactions with the biologically active natriuretic receptors. VNP may also interact with the clearance receptor so as to displace both ANP and CNP from this silent receptor and potentiate vasoactive responses. Last, VNP may interact with an unknown receptor that is not activated by either ANP or CNP. Further studies are required to elucidate these possible mechanisms.

In conclusion, the present studies report the biological actions of a new synthetic peptide, termed VNP, that possesses the 22-amino acid structure of CNP with the $\mathrm{COOH}$ terminus of ANP. The biological actions of natriuresis in vivo and vasodilation and venodilatation in vitro suggest its interaction with the distinct receptors that mediate the natriuretic actions of ANP and venodilating actions of CNP.

\section{Acknowledgments}

We gratefully thank Ben Madden, Jane Liebenow, Denise Heublein, Laurence Aarhus, Dr. Ali A. Khraibi, and Dr. Mimura Yoshikazu for their technical assistance.

This work was supported in part by grants from the American Heart Association, Minnesota Affiliate (MHA-103), the National Heart, Lung, and Blood Institute (HL-36634 and HL-07111), and the Mayo Foundation.

\section{References}

1. De Bold, A. J., H. B. Borenstein, A. T. Veress, and H. Sonnenberg. 1981. A rapid and potent natriuretic response to intravenous injection of atrial myocardial extracts in rats. Life Sci. 28:89-94.

2. Burnett, J. C. Jr., J. P. Granger, and T. J. Opgenorth. 1984. Effects of synthetic atrial natriuretic factor on renal function and renin release. Am. J. Physiol. 247:F863-F866. 
3. Burnett, J. C. Jr., P. C. Kao, D. C. Hu, D. Heser, D. Heublein, J. Granger, T. Opgenorth, and G. Reeder. 1986. Atrial natriuretic factor in normal subjects and heart failure patients. Science (Wash. DC). 231:1145-1147.

4. Koller, K. J., D. G. Lowe, G. L. Bunnett, N. Minamino, K. Kangawa, H. Matsuo, and D. V. Goeddel. 1991. Selective activation of the B-natriuretic peptide receptor by C-type natriuretic peptide (CNP). Science (Wash. DC). 252:120-123.

5. Wilcox, J. N., A. Augustine, D. V. Goeddel, and D. G. Lowe. 1991. Differential regional expression of three natriuretic peptide receptor genes within primate tissues. Mol. Cell. Biol. 11:3454-3462.

6. Currie, M. G., D. M. Geller, B. R. Cole, N. R. Siegel, K. F. Fok, S. P. Adams, S. R. Eubanks, G. R. Galluppi, and P. Needleman. 1984. Purification and sequence analysis of bioactive atrial peptides (atriopeptins). Science (Wash. DC). 223:67-69.

7. Komatsu, Y., K. Nakao, S. Suga, Y. Ogawa, M. Mukoyama, H. Arai, G. Shirakami, K. Hosoda, O. Nakagawa, and N. Hama. 1991. C-type natriuretic peptide in rats and humans. Endocrinology. 129:1104-1106.

8. Schulz, S., S. Singh, R. A. Bellet, G. Singh, D. J. Tubb, H. Chin, and D. L. Garbers. 1989. The primary structure of a plasma membrane guanylate cyclase demonstrates diversity within this few receptor family. Cell. 58:1155-1162.

9. Stingo, A. J., A. L. Clavell, L. L. Aarhus, and J. C. Burnett, Jr. 1992 Cardiovascular and renal actions of C-type natriuretic peptide. Am. J. Physiol. 262:H308-H312.
10. Clavell, A. L., A. J. Stingo, C. M. Wei, D. M. Heublein, and J. C. Burnett, Jr. 1993. C-type natriuretic peptide: a selective cardiovascular peptide. Am. J. Physiol. 264:R290-R295.

11. Wei, C. M., L. L. Aarhus, V. M. Miller, and J. C. Burnett, Jr. 1993. The action of C-type natriuretic peptide in isolated canine arteries and veins. Am. J. Physiol. 264:H71-H73.

12. Heublein, D. M., A. L. Clavell, A. J. Stingo, A. Lerman, L. Wold, and J. C. Burnett, Jr. 1992. C-type natriuretic peptide immunoreactivity in human breast vascular endothelial cells. Peptides (Elmsford). 13:1017-1019.

13. Stingo, A. J., A. L. Clavell, D. M. Heublein, C. M. Wei, M. R. Pittelkow, and J. C. Burnett, Jr. 1992. Presence of C-type natriuretic peptide in cultured human endothelial cells and plasma. Am. J. Physiol. 263:H1318-H1321.

14. Suga, S., K. Nakao, $H$. Itoh, $Y$. Komatsu, $Y$. Ogawa, N. Hama, and $H$. Imura. 1992. Endothelial production of C-type natriuretic peptide and its marked augmentation by transforming growth factor- $\beta$. Possible existence of "vascular natriuretic peptide system." J. Clin. Invest. 90:1145-1149.

15. Steiner, A. L., C. W. Parker, and K. M. Kipnis. 1972. Radioimmunoassay for cyclic nucleotidase. I. Preparation of antibodies and iodinated cyclic nucleotidase. J. Biol. Chem. 247:1106-1113.

16. Hughes, A. D., H. Nielsen, S. Thom, G. N. Martin, and P. S. Sever. 1987. The effect of atrial natriuretic peptide on human blood vessels. J. Hypertens. 5(Suppl. 5):51-53.

17. Brown, J., and Z. Zuo. 1992. Renal receptors for atrial and C-type natriuretic peptides in the rat. Am. J. Physiol. 263:F89-F96. 